\title{
Edad y Cirugía. Tecnología y Humanismo. ¿Qué lugar le adjudicamos a la ética?
}

\section{Age and Surgery. Technology and Humanism}

El tema EDAD y CIRUGÍA se puede enfocar rápidamente desde dos ángulos:

El primer enfoque es el hecho que hoy tratamos pacientes de mayor edad, a muchos de los cuales no le habríamos dado ninguna posibilidad de tratamiento hace solamente 20 o 30 años. Solo pensar en una cirugía radical por cáncer en una persona de 75 o más años... Debemos poner énfasis en cuidar la ética, intentar curar cuando es razonable y en otros casos saber acompañar como médicos, saber cuidar y bien utilizar los recursos... Debemos pensar en el concepto de Calidad de Vida, que a edades mayores podría entenderse como tener una mente ágil, pocos dolores corporales, corazón alegre, estómago entonado, cierta autonomía y compañia... Debemos colaborar en mejorar, o al menos alterar lo menos posible ese estado de homeostasis, que algunas personas de muchos años tienen la gracia de disfrutar.

\section{El segundo tema es la edad de los cirujanos...}

Como sociedad debemos plantearnos el aprovechamiento de la madurez y experiencia de cirujanos que hoy se plantean el retiro cuando todavía están en la plenitud de sus capacidades, en alguna circunstancia tal vez no tanto físicas, pero muchas veces si plenos en capacidad de organización, de análisis sobre aprovechamiento de recursos, de planes de desarrollo, y tantas otras cosas.

Apasionarse es enfrentar los tiempos de los procesos, no solo el resultado como fin en si mismo. La pasión entonces hace pareja con la paciencia. En el otro rincón están la abulia y la apatía. Suele decirse que los jóvenes representan a la pasión, pero la pasión puede ser atropello si la misma no es ubicada en el momento adecuado. Para lograr la mayor eficacia como sociedad, será necesaria una cuota de pasión mixturada con la paciencia que da la experiencia de saber elegir los momentos y los caminos más convenientes.

Pero, ¿quiénes son los más adecuados/capacitados para dirigir/guiar? ¿Existe un método para detectar esas personas de mayor experiencia, de mayor sentido común? Lamentablemente NO existe. Se recomienda leer la "Apología" de Sócrates, donde al sabio, a medida que avanza en sus conocimientos, se le hace más evidente que es muy poco lo que sabe ("solo sé, que no se nada"), y que es más lo que le falta aprender. Sin embargo, eso no quita el hecho de que se pueda crecer en experiencia para afrontar los procesos de crecimiento en el conocimiento y en la aplicación de esos conocimientos, en este caso a atender pacientes, intentar curarlos, e implementar los sistemas organizativos para tal fin, y para evolucionar en la mejoría de dichos procesos.

No es intención de este escrito establecer las máximas que resuelvan todos estos problemas, sino solamente disparar las preguntas que nos hagan pensar a todos y que nos acerquen a una posible solución. Resulta claro a cualquier persona inteligente que para una mayor eficacia en el funcionamiento como sociedad deberemos unir fuerzas entre los más jóvenes y pujantes con los más experimentados y pensantes... no será fácil seleccionar a estos últimos... ¿quién debería comandar ese proceso de selección? Es probable que los mejores proyectos de liderazgo sean los que se establecen espontáneamente, en base a la experiencia reiterada de quien demuestra una y otra vez buena capacidad en la toma de decisiones. No resultan selecciones fáciles en muchos casos. También es necesario saber dar un paso al costado. Es muy probable que el mejor factor de selección esté en la ETICA de cada uno, de estar dispuesto a colaborar y dar un poco más por la sociedad, o en otros momentos saber reconocer que tal vez otro lo pueda hacer mejor que uno.

Pero en estos años, la valoración ética no parece ser un valor mensurable o valedero para en este caso seleccionar gente con capacidad de colaboración... resulta mucho más importante una "tabulación" en 
base a parámetros más objetivos (cursos, publicaciones, etc., etc.). De ninguna manera se pretende poner en duda la utilidad de las valoraciones objetivas, solamente resaltar lo olvidada que parecería haber quedado la valoración de la ética personal en estos procesos de selección.

Finalmente, nunca debemos olvidar que todo debe estar orientado a ATENDER MEJOR A NUESTROS PACIENTES... no debemos olvidar ese punto... Colaborar con los jóvenes pujantes no solo significa ayudar a desarrollar un Departamento de Cirugía que tenga gran producción científica, o que duplique los ingresos económicos, sino que también atienda bien a los pacientes, no solo técnicamente, sino también desde el aspecto humanitario.

La medicina necesita un balance entre técnica y humanismo... Las generaciones mayores deben ayudar, de una forma inteligente, a no perder de vista estos temas... y las nuevas y pujantes generaciones deberán saber respetar la experiencia de quienes los preceden.

Es importante recordar que no tratamos enfermedades ni órganos, y que por más especialistas que seamos sigue estando frente a nosotros una persona/paciente afligido por su enfermedad, que espera excelencia técnica, pero además también una palabra de aliento y/o consuelo. La Madre Teresa de Calcuta supo resumir de manera extraordinaria en una frase cuando se refería a la ayuda que se le puede dar/ofrecer a la gente humilde... "y tengamos en cuenta que nuestros pacientes siempre están en un estado de indefensión frente a la enfermedad... en la enfermedad todos nos igualamos y pasamos a ser todos humildes"... la Madre Teresa decía: "ellos no necesitan tanto de vuestro dinero... ellos necesitan UN ABRAZO".

Que los grandes avances tecnológicos no nos hagan perder de vista que tratamos personas humildes e indefensas frente a la enfermedad, y que no solo necesitan recursos y capacidades tecnológicas bien utilizadas, sino también cierto compromiso humanitario.

Para terminar quiero compartir con ustedes un escrito que he leido hace muy poco, y que expone muy bien la importancia del encuadre ético que debemos darle a nuestra profesión de médicos cirujanos en este caso, pero que es aplicable a cualquier otra profesión. Escribía Mons. Mariano Fazio:

"El mundo reclama una revolución ética. En el pasado se ha propuesto que los grandes problemas del hombre podrían solucionarse mediante la técnica, dejando de lado la ética. En ese contexto, la medicina curaría las enfermedades, la economía acabaría con la pobreza, las instituciones democráticas llevarían automáticamente al bien común. La técnica resolvería los problemas sin que fuera necesario el compromiso personal y social de cada uno. Se soñó, allá por el siglo XVIII, con un sistema de gobierno que fundiera el egoísmo en un resultado positivo. Confiaban en que era posible diseñarlo de tal modo que el Estado de derecho asegurara con sus mecanismos técnicos la consecución de la paz y el bienestar. La ética sería prescindible: el sistema subsidiaría cierto grado de inmoralidad humana.

Este proceso se ha desarrollado, y ha dado algunos beneficios y algunos frutos amargos. Pues la técnica cumple un rol fundamental, pero incompleto: la ética debe ser un componente esencial del desarrollo. Sin ella, la economía sólo beneficia a unos pocos ricos, la medicina se vuelve un negocio, y la política, una lucha despiadada por el poder.

Es verdad que lo humano está teñido de sombras. Pero, siempre que hablamos de sombras, implicamos una luz que las genera. Por eso, cabría preguntarse: ¿dónde está esa luz detrás de las sombras? ”

Todos sabemos bien donde buscar aprender los nuevos avances tecnológicos. Cada uno deberá saber buscar en su interior donde está esa luz que ilumina las sombras y que mantiene vivo el sentido del juramento hipocrático que hacemos cuando nos recibimos de médicos.

Dr. Luis Durand Figueroa Jefe Sección Esófago-Estómago-Duodeno Servicio de Cirugía Gastroenterológica-Departamento de Cirugía Hospital de Clínicas-Universidad de Buenos Aires. Buenos Aires, Argentina. 